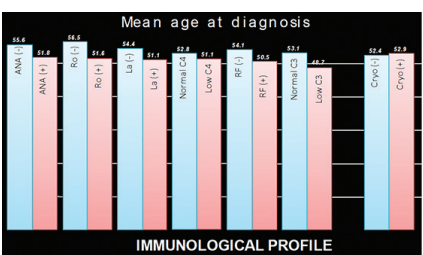

Abstract THU0277 - Figure 2

Patients with positive immunological markers had a younger diagnostic age, except for cryoglobulins ( $p<0.001$ all comparisons).

Patients without systemic activity (ESSDAl score $=0$ ) were diagnosed at an older age (55.5 vs 52.1 yrs in those with systemic activity, $p<0.001$ ). There was a wide variation in the age at diagnosis of patients presenting with systemic activity according to the organ involved.

Conclusion: Age at diagnosis plays a key role in the glandular and systemic phenotype expressed by primary SjS patients at the time of diagnosis.

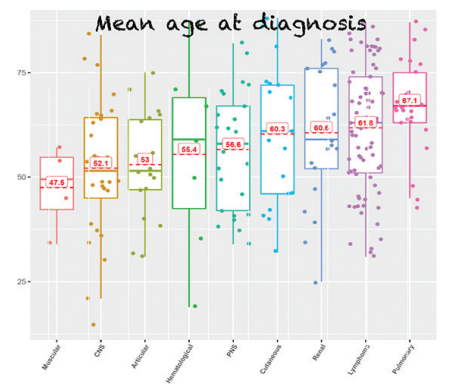

Abstract THU0277 - Figure 3

Disclosure of Interests: Soledad Retamozo: None declared, Nihan AcarDenizli: None declared, Wan Fai Ng: None declared, Ildiko Fanny Horváth: None declared, Astrid Rasmussen: None declared, Raphaèle Seror Grant/research support from: Pfizer, Consultant for: Bristol-Myers Squibb, Pfizer, Amgen, Eli Lilly, Roche, Celgene, GlaxoSmithKline, Medlmmune, Xiaomei Li: None declared, Chiara Baldini: None declared, Jacques-Eric Gottenberg Grant/research support from: Bristol-Myers Squibb, Grant/ research support from: Bristol-Myers Squibb, Consultant for: Bristol-Myers Squibb, Lilly, Pfizer, Sanofi-Genzyme, UCB Pharma, Consultant for: Bristol-Myers Squibb, Eli Lilly, UCB, Sanofi-Genzyme, Pfizer, Pulukool Sandhya: None declared, Luca Quartuccio: None declared, Roberta Priori: None declared, Gabriela Hernandez-Molina: None declared, Berkan Armagan: None declared, Aike A. Kruize: None declared, Seung-Ki Kwok: None declared, Marika Kvarnstrom: None declared, Sonja Praprotnik: None declared, Damien Sene: None declared, Elena Bartoloni Bocci: None declared, Roser Solans-Laqué: None declared, Maureen Rischmueller Consultant for: Abbvie, Bristol-Meyer-Squibb, Celgene, Glaxo Smith Kline, Hospira, Janssen Cilag, MSD, Novartis, Pfizer, Roche, Sanofi, UCB, Thomas Mandl: None declared, Yasunori Suzuki: None declared, David Isenberg: None declared, Valeria Valim: None declared, Agata Sebastian: None declared, Gunnel Nordmark: None declared, Hendrika Bootsma: None declared, Hideki Nakamura: None declared, Roberto Giacomelli Grant/research support from: Pfizer, Actelion, Speakers bureau: Actelion, Bristol-Myers Squibb, Merck Sharp \& Dohme, Abbvie, Pfizer, Sobi, Roche, Valerie Devauchelle-Pensec Grant/research support from: Roche-Chugai, Speakers bureau: MSD, BMS, UCB, Roche, Benedikt Hofauer Consultant for: Consultant for Galvani Bioelectronics for the area of sleep disorders., Michele Bombardieri Grant/research support from: Celgene, Consultant for: Medimmune, Virginia Fernandes Moça Trevisani: None declared, Daniel Hammenfors: None declared, Sandra Pasoto: None declared, Tamer A Gheita: None declared, Fabiola Atzeni: None declared, Jacques Morel: None declared, Cristina Vollenveider: None declared, Sandra Consani-Fernández: None declared, Xavier Mariette Grant/research support from: Servier, Consultant for: AstraZeneca, Bristol-Myers Squibb, GlaxoSmithKline, Janssen, Pfizer, UCB Pharma, Manuel Ramos-Casals: None declared, Pilar Brito-Zerón: None declared DOI: 10.1136/annrheumdis-2019-eular.2428

\section{THU0278 \\ ADVERSE PREGNANCY OUTCOMES (APOS) AFTER MULTI-PROFESSIONAL FOLLOW-UP IN WOMEN AFFECTED BY SYSTEMIC LUPUS ERYTHEMATOSUS (SLE). REPORT FROM A SINGLE CENTER IN} SOUTHERN SWEDEN.

Muna Saleh $^{1}$, Andreas Jonsen ${ }^{2}$, Anders Bengtsson ${ }^{2}$, Michele Compagno ${ }^{2}$.

${ }^{1}$ Rheumatology, Helsingborg, Department of Clinical Sciences, Helsingborg, Sweden; ${ }^{2}$ Lund, Department of Clinical Sciences Lund, Rheumatology, Lund, Sweden

Background: Systemic lupus erythematosus (SLE) often affects women in childbearing age. Modern management of SLE patients has improved the pregnancy outcomes over the last years. However, there is still an increased risk of maternal, fetal and neonatal complications (1).

Objectives: We report our experience in the multi-professional follow-up of pregnant women affected by SLE. Our aim was to investigate the association of potential risk factors with the occurrence of adverse pregnancy outcomes (APOs).

Methods: We selected the patients who have had one or more pregnancies, between January 2002 and January 2018, among all the SLE patients at the Department of Rheumatology, University Hospital in Lund, Sweden. Longitudinal clinical and laboratory data from rheumatology and obstetrics units, as well as from neonatal units, were collected and analyzed. We assessed the association between APOs and putative SLErelated risk factors as well as known risk factors in the selected population.

Results: We investigated the outcome of 59 pregnancies in 28 SLE patients. Eighteen (64.3\%) patients had one or more APOs. Forty-four $(74.6 \%)$ pregnancies terminated with a delivery, whereof $36(61 \%)$ term pregnancies and $8(13.6 \%)$ before 36 gestational weeks. Caesarean section terminated $13(29.5 \%)$ pregnancies. Thirteen (22\%) miscarriages and two $(3.4 \%)$ intentional abortions were recorded. HELLP syndrome occurred in $1(1.7 \%)$ and pre-eclampsia in $11(18.6 \%)$ gestations. Among 16 cases of fetal growth restriction, $5(8.5 \%)$ gestations resulted in intrauterine growth restriction, $1(1.7 \%)$ in a small for gestational age baby and $10(24.4 \%)$ in low birth weight. No cases of eclampsia, stillbirths or congenital heart disease were recorded. Neonatal lupus erythematosus occurred in $1(1.7 \%)$ baby. APOs were associated with anti-phospholipid syndrome and/or presence of anti-phospholipid antibodies (OR $4.5-p=$ 0.009). Previous renal involvement was associated with APOs (OR 5.9 $p=0.005$ ) and with fetal growth restriction (OR $11-p=0.03$ ). Active disease (SLEDAI >3) six months before or during pregnancies was associated with miscarriage (OR $13-p=0.02$ ). Pre-eclampsia and pre-term deliveries were not significantly associated with any of the investigated risk factors.

Conclusion: One or more APOs occurred in the majority of patients in our study and a few severe outcomes were recorded. Our experience suggests that the presumptive risk factors for APOs in SLE patients are disease related, such as high disease activity six months before or during pregnancies, previous renal involvement and anti-phospholipid syndrome/antibodies.

\section{REFERENCE:}

1 IM Jakobsen, RB Helmig \& K Stengaard-Pedersen (2015) Maternal and foetal outcomes in pregnant systemic lupus erythematosus patients: an incident cohort from a stable referral population followed during 1990 2010,Scandinavian Journal of Rheumatology, 44:5, 377-384, DOI: 10.3109/03009742.2015.1013982

Disclosure of Interests: None declared DOI: 10.1136/annrheumdis-2019-eular.7977

\section{THU0279 POLYUNSATURATED FATTY ACIDS (PUFAS) AND SPECIALIZED PRO-RESOLVING MEDIATORS (SPMS) ARE DECREASED IN PLASMA AND SERUM FROM SLE PATIENTS COMPARED TO HEALTHY CONTROLS}

Julia Davis-Porada ${ }^{1}$, Charles Serhan ${ }^{2}$, Paul Norris $^{2}$, Peter Lipsky ${ }^{3}$, Jane E. Salmon ${ }^{1}$. ${ }^{1}$ Hospital for Special Surgery, New York, United States of America; ${ }^{2}$ Center for Experimental Therapeutics and Reperfusion Injury; Department of Anesthesia, Perioperative and Pain Medicine; Brigham and Women's Hospital and Harvard Medical School, Boston, United States of America; ${ }^{3}$ AMPEL BioSolutions, Charlottesville, United States of America

Background: Systemic lupus erythematosus (SLE) is an autoimmune disease with persistent, inflammatory mediated organ damage. It has been suggested that omega-3-polyunsaturated fatty acids (PUFAs) are low in SLE patients and that 
supplementation with omega-3 PUFAs might be beneficial. Omega-3 PUFAs can be metabolized to specialized pro-resolving mediators (SPM) in inflamed tissues. PUFAs, eicosapentaenoic acid (EPA) and docosahexaenoic acid (DHA), give rise to protectins and E-series and D-series resolvins, respectively. These SPMs help promote tissue repair and healing in addition to reducing neutrophil infiltration.

Objectives: To investigate (1) if SMPs can be measured in lupus patient blood and (2) whether EHA and DHA and SPMs were dysregulated in lupus patients compared to controls.

Methods: Blood samples were collected from 12 patients enrolled in the Autoimmune Disease Registry and Repository, a single center registry (1996-present) of patients meeting ACR SLE classification criteria. Samples were collected from 12 non-SLE-controls who were age ( \pm 5 years) and race/ethnicity matched. Metabolomic profiling via tandem mass spectrometry (LC-MS-MS) was performed on serum and plasma to assess the PUFA and SPM levels.

Results: Levels of EPA and DHA were highly correlated in serum and plasma. Both EPA and DHA were significantly decreased in SLE patients compared to controls (Table 1). Neither plasma nor serum DHA or EPA levels was correlated with disease activity assessed by SLEDAI score. SPMs including PD1 and RvE1 as well as their precursors, 17-HDHA and 18-HEPE, were identified in plasma and serum samples from SLE patients. Plasma levels of 17-HDHA, as well as serum levels of PD1, 17-HDHA, and 18-HEPE tended to be reduced in SLE (Table 1). The SLE patients with a history of nephritis had significantly lower levels of DHA $(p=0.03)$, EPA $(p=0.05)$, 18-HEPE $(p=0.03)$, and 17-HDHA $(p=0.04)$ than SLE patients without nephritis.

Conclusion: SLE patients have lower levels of circulating EPA and DHA, the substrates for SPMs, relative to individuals without SLE. Lower levels of these PUFAs and some SPMs are associated with history of nephritis. Additionally, the levels of PD1, 17-HDHA, and 18-HEPE were measurable in SLE serum and plasma and tended to be reduced, especially in subjects with lupus nephritis. SPMs suppress the production of inflammatory mediators and promote resolution of inflammation. The lower levels of PUFAs and SPMs could contribute to the likelihood of developing lupus nephritis. Further evaluation of this relationship is warranted.

Abstract THU0279 - Table 1. Metabolipidomics of SLE and Control Serum

\begin{tabular}{|l|l|l|l|}
\hline $\begin{array}{l}\text { Metabolite (in serum) } \\
\text { mean, (SD) }\end{array}$ & Control $(n=12)$ & SLE $(n=12)$ & P Value \\
\hline EPA & $6779.7(3985.2)$ & $2822.9(3082.9)$ & 0.013 \\
\hline DHA & $19584.0(15785.1)$ & $7664.0(5613.3)$ & 0.003 \\
\hline PD1 & $55.0(128.6)$ & $23.3(57.1)$ & 0.489 \\
\hline 17-HDHA & $47.4(25.3)$ & $15.7(14.9)$ & $<0.001$ \\
\hline 18-HEPE & $20.8(7.1)$ & $17.3(9.8)$ & 0.195 \\
\hline
\end{tabular}

Metabolite (in serum) mean, (SD) Control $(n=12)$ SLE $(n=12) P$ Value

Disclosure of Interests: Julia Davis-Porada: None declared, Charles Serhan: None declared, Paul Norris: None declared, Peter Lipsky Consultant for: Consulting fees from Horizon Pharma, Jane E. Salmon Shareholder of: Biogen-Idec, BMS, Johnson \& Johnson, Regeneron, Merck, Grant/ research support from: UCB, Consultant for: BMS, Ionis

DOI: 10.1136/annrheumdis-2019-eular.2126

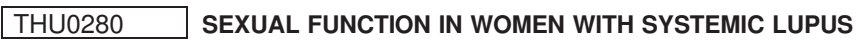 ERYTHEMATOSUS: A CASE-CONTROL STUDY}

Griselda Serna-Peña ${ }^{1}$, Iris Jazmin Colunga-Pedraza ${ }^{1}$, Miguel Angel VillarrealAlarcón ${ }^{1}$, Ileana Cecilia Reynosa-Silva ${ }^{1}$, Sergio Andrés Castillo-Torres ${ }^{2}$, Dionicio Ángel Galarza-Delgado ${ }^{1}$. ${ }^{1}$ Hospital Universitario Dr José Eleuterio Gonzalez, Rheumatology, Monterrey, Mexico; ${ }^{2}$ Hospital Universitario Dr José Eleuterio Gonzalez, Neurology, Monterrey, Mexico

Background: Normal sexual function consists in the transition, during sexual activity, through the phases of excitement to relaxation without problems, and with a feeling of pleasure, satisfaction and fulfillment (1). The effect of systemic lupus erythematosus (SLE) in sexual function has been one of the least studied areas, but it is thought that some diseaserelated characteristics could have a negative effect. There are few previous studies that investigate sexual function in SLE, general results indicate a negative impact (2).
Objectives: The main aim of this study is to determine if there is an altered sexual function in Mexican women with SLE and compare if it occurs in a greater proportion than in healthy women.

Methods: A case-control study with 102 Mexican women between 18 and 60 years, with SLE diagnosis (according to SLICC 2012 criteria) and a control group of healthy women $(n=156)$ matched by age. Patients were excluded if they couldn't answer the questionnaires reliably and pregnant women. They were asked about the presence of active sexual life in the last month and the Female Sexual Function Index (FSFI) self-questionnaire was applied. Variables between groups were compared with Chisquare and Mann $U$ Whitney test.

Results: Baseline demographic characteristics between groups are shown in table 1. Women with SLE had less sexual activity, during the last month, than controls $(63.7 \%$ vs $77.5 \%, p=0.01)$. Out of the total women included, the FSFI was applied only to those that had an active sexual life, 65 with SLE and 121 healthy women. Sexual disfunction (<26.5 points) was found in $28 \%$ women with SLE and in $22 \%$ of controls, with no significant differences $(p=0.4)$. In the SLE group, a worse total score was found, as well as alteration in the desire and excitation domains when compared to healthy women (Table 2). In the multivariate linear regression analysis (using FSFI as the variable), no relationship was found with any demographic or disease-related variables.

Abstract THU0280 - Table 1. Comparison of demographic variables between the SLE and control group.

\begin{tabular}{|c|c|c|c|}
\hline & $\begin{array}{c}\text { Control group } \\
(n=156)\end{array}$ & $\begin{array}{l}\text { SLE group } \\
(n=102)\end{array}$ & $p^{*}$ \\
\hline Age, years $( \pm S D)$ & $33.2( \pm 10.8)$ & $36.3( \pm 11.6)$ & 0.030 \\
\hline Civil Status & & & 0.977 \\
\hline Single, $\mathbf{n}(\%)$ & $56(35.9)$ & 38 (37.3) & \\
\hline Married, n (\%) & $76(48.7)$ & $47(46.1)$ & \\
\hline Divorced, n (\%) & $8(5.1)$ & $6(5.9)$ & \\
\hline $\begin{array}{l}\text { Domestic partnership, } \mathrm{n} \\
(\%)\end{array}$ & $16(10.3)$ & $11(10.8)$ & \\
\hline $\begin{array}{l}\text { Widowed, n (\%) } \\
\text { Education }\end{array}$ & $0(0)$ & $0(0)$ & \\
\hline$<10$ Years, $\mathrm{n}(\%)$ & $91(58.3)$ & $58(56.9)$ & 0.815 \\
\hline Menopause, n (\%) & $21(13.5)$ & $23(22.5)$ & 0.058 \\
\hline Has children, $\mathbf{n}(\%)$ & $82(52.6)$ & $69(67.6)$ & 0.016 \\
\hline
\end{tabular}

*-Mann U Whitney or Chi-Square test according to type of variable. SD - Standard Deviation.

Abstract THU0280 - Table 2. Female Sexual Function Index according to group.

\begin{tabular}{lccc}
\hline $\begin{array}{l}\text { Female Sexual Function } \\
\text { Index }\end{array}$ & $\begin{array}{c}\text { Control group } \\
(\mathrm{n}=121)\end{array}$ & $\begin{array}{c}\text { SLE group } \\
(\mathrm{n}=65)\end{array}$ & $p^{*}$ \\
\hline Sexual disfunction, $n(\%)$ & $27(22)$ & $18(28)$ & 0.414 \\
Total, 2-36 points & $30.5(34.8)$ & $29.3(25.7)$ & $\mathbf{0 . 0 1 7}$ \\
Desire (1.2-6) & $5.1(6)$ & $4.5(4.8)$ & $<0.001$ \\
Excitation (0-6) & $5.2(6)$ & $4.8(4.8)$ & $\mathbf{0 . 0 4 6}$ \\
Lubrication (0-6) & $5.6(6)$ & $5.2(4.8)$ & 0.181 \\
Orgasm (0-6) & $4.2(4.8)$ & $4.2(4.2)$ & 0.254 \\
Satisfaction (0.8-6) & $5.4(6)$ & $5.4(4.8)$ & 0.409 \\
Pain (0-6) & $5.6(6)$ & $5.2(4.8)$ & 0.590 \\
\hline
\end{tabular}

*-Mann U Whitney or Chi-square test according to type of variable.

Conclusion: Women with SLE, in this study, have less sexual activity than healthy women, but no greater sexual disfunction. However, they have a worse performance in the desire and excitation areas. This alteration did not show a relation with demographic nor disease-related variables. The abnormality found could be explained by a psychosocial factor not evaluated in this study.

\section{REFERENCES}

[1] Tristano AG. The impact of rheumatic diseases on sexual function. Rheumatol Int. 2009. doi:10.1007/s00296-009-0850-6

[2] Daleboudt GMN, et al. The impact of illness perceptions on sexual functioning in patients with systemic lupus erythematosus. J Psychosom Res. 2013 